\title{
DICER1 hotspot mutations in non-epithelial gonadal tumours
}

\author{
L Witkowski ${ }^{1,2,3}$, J Mattina², S Schönberger ${ }^{4}$, M J Murray 5,6, D G Huntsman7, J S Reis-Filho8,
} W G McCluggage ${ }^{9}$, J C Nicholson ${ }^{5}$, N Coleman ${ }^{6}$, G Calaminus ${ }^{10}$, D T Schneider ${ }^{11}$, J Arseneau ${ }^{12}$, C J R Stewart ${ }^{13}$ and W D Foulkes ${ }^{\star 1,2,3,14}$

${ }^{1}$ Department of Oncology and Human Genetics, Program in Cancer Genetics, McGill University, Montreal, Quebec, Canada; ${ }^{2}$ Department of Medical Genetics, Lady Davis Institute and Segal Cancer Centre, Jewish General Hospital, McGill University, Montreal, Quebec, Canada; ${ }^{3}$ Department of Human Genetics, McGill University, Montreal, Quebec, Canada; ${ }^{4}$ Department of Paediatric Haematology and Oncology, University of Bonn, University Children's Hospital, Bonn, Germany; ${ }^{5}$ Department of Paediatric Oncology and Haematology, Cambridge University Hospitals NHS Foundation Trust, Cambridge, UK; ${ }^{6}$ Department of Pathology, University of Cambridge, Cambridge, UK; ${ }^{7}$ Departments of Pathology, Vancouver General Hospital, Centre for Translational and applied Genomics, the British Columbia Cancer Agency and the Genetic Pathology Evaluation Centre, Vancouver, British Columbia, Canada; ${ }^{8}$ Department of Pathology, Memorial Sloan-Kettering Cancer Center, New York, NY, USA; ${ }^{9}$ Department of Pathology, Royal Group of Hospitals Trust, Belfast, UK; ${ }^{10}$ Department of Paediatric Haematology and Oncology, University of Münster, Münster, Germany; ${ }^{11}$ Clinic of Paediatrics, Municipal Hospital Dortmund, Dortmund, Germany; ${ }^{12}$ Department of Pathology, McGill University, Montreal, Quebec, Canada; ${ }^{13}$ Department of Histopathology, King Edward Memorial Hospital, Perth, Australia and ${ }^{14}$ Department of Medical Genetics, Research Institute, McGill University Health Centre, Montreal, Quebec, Canada

Background: Non-epithelial gonadal tumours largely comprise sex cord-stromal tumours (SCSTs) and germ cell tumours (GCTs). Specific somatic mutations in DICER1, a microRNA maturation pathway gene, have been identified in these tumours. We conducted a study that aimed to confirm, refine and extend the previous observations.

Methods: We used Sanger sequencing to sequence the RNase IIla and IIlb domains of DICER1 in 154 gonadal tumours from 135 females and 19 males, as well as 43 extra-gonadal GCTs from 26 females and 17 males.

Results: We identified heterozygous non-synonymous mutations in the RNase IIIb domain of DICER1 in 14/197 non-epithelial tumours (7.1\%). Mutations were found in 9/28 SCSTs (32\%), 5/118 gonadal GCTs (4.2\%), 0/43 extra-gonadal GCTs and 0/8 miscellaneous tumours. The 14 mutations affected only five residues: E1705, D1709, E1788, D1810 and E1813. In all five patients where matched and constitutional DNA was available, the mutations were only somatic. There were no mutations found in the RNase Illa domain.

Conclusion: More than half (8/15) of Sertoli-Leydig cell tumours (SLCTs) harbour DICER1 mutations in the RNase IIIb domain, while mutations are rarely found in GCTs. Genetic alterations in SLCTs may aid in classification and provide new approaches to therapy.

Non-epithelial ovarian tumours consist of sex cord-stromal tumours (SCSTs), germ cell tumours (GCTs), as well as other miscellaneous neoplasms such as lymphomas and soft tissue tumours (Table 1 (Scully, 1987)). Sex cord-stromal tumours and
GCTs, respectively, comprise $8 \%$ and $3 \%$ of all ovarian malignancies in Western countries (Talerman and Vang, 2011; Young, 2011; Low et al, 2012). Although SCSTs can arise in women of all ages (Young, 2011), GCTs often develop in adolescence or early

*Correspondence: Dr WD Foulkes; E-mail: william.foulkes@mcgill.ca

Received 6 June 2013; revised 22 September 2013; accepted 23 September 2013; published online 17 October 2013

(c) 2013 Cancer Research UK. All rights reserved 0007 - 0920/13 
adulthood and almost $70 \%$ of ovarian tumours occurring before the age of 20 years are germ cell in type (Low et al, 2012). GCTs can arise in both male and female patients; in adults, 90\% develop in the gonad and the other $10 \%$ arise extra-gonadally, while in children, the tumours arise in gonadal and extra-gonadal sites with similar frequency (Giambartolomei et al, 2009; Arora et al, 2012). These tumours are sub-classified depending on the degree and direction of differentiation: germinomas (dysgerminomas in the ovary and seminomas in the testis), embryonal carcinomas, yolk sac tumours (also known as an endodermal sinus tumour), polyembryomas, choriocarcinomas, teratomas (mature and immature) and mixed malignant GCTs, which are composed of more than one tumour type (Table 1 (Scully, 1987)). Sex cord-stromal tumours are further categorised into granulosa-stromal cell tumours, Sertoli-stromal cell tumours (including Sertoli-Leydig cell tumours (SLCTs)), mixed and unclassified SCST, and steroid cell tumours (Table 1 (Scully, 1987)). The prognosis of SCSTs and GCTs is generally favourable, with an overall survival of $89 \%$ and 80\%, respectively (Schneider et al, 2003; Luis and Coleman, 2011).

In addition to these non-epithelial tumours, other very rare and highly malignant ovarian tumours exist that fall under the 'miscellaneous tumours' category, with some categorised as small round cell tumours of childhood (Scully, 1987). These include, but are not limited to, small-cell carcinoma of the ovary, hypercalcaemic type and rhabdomyosarcoma (Table 1). Owing to the rarity of these tumours, they are difficult to comprehensively study and little is known about their biology or genetics.

DICER protein, encoded by the DICER1 gene, has many functions, including virus and transposon defence, chromatin regulation, centromere integrity and most notably, control of gene expression as part of the microRNA (miRNA) pathway (Murchison and Hannon, 2004). MiRNAs are small (20-22 nucleotide) non-coding RNAs that regulate the translation of downstream target genes at their $3^{\prime}$-untranslated region and, as such, have an important role in virtually all biological processes. A mutation in any component of the miRNA processing pathway can potentially modify the expression of miRNAs, causing dysregulation of their target mRNA expression. MiRNAs are generally downregulated in cancer (Lu et al, 2005) and have been shown to function as both oncogenes and as tumour suppressors in their own right. As a member of the RNase III endonuclease family, DICER measures and cleaves all precursor miRNAs into mature miRNAs, and hence is an essential part of this pathway.

In recent years, the role of DICER in cancer progression and prognosis has been extensively studied. In several cancers, including lung, breast, ovarian and endometrial carcinoma, low levels of DICER expression are associated with poorer survival rates. Conversely, in prostate and colorectal cancers, higher expression of DICER has been shown to be associated with a worse prognosis (Bahubeshi et al, 2011). DICER1 is the only gene in the miRNA pathway in which germline mutations predispose to a Mendelian disorder, which is characterised by a range of mainly paediatric-onset cancers (Bahubeshi et al, 2011). Germline mutations were first discovered in patients with pleuropulmonary blastoma (PPB), a rare lung tumour, who all had a family history of $\mathrm{PPB}$ or the related familial tumour dysplasia syndrome (PPBFTDS, Online Mendelian Inheritance in Man (OMIM) number, 601200 (Hill et al, 2009)). This syndrome commonly includes cystic nephroma, ovarian SCSTs (particularly SLCTs), and multinodular goitre (Bahubeshi et al, 2011). Since then, additional rare neoplasms have been included in the DICER1 syndrome, when they were shown to be associated with deleterious germline DICER1 mutations, including cervical embryonal rhabdomyosarcoma (ERMS), ciliary-body medulloepithelioma, pituitary blastoma, cervical primitive neuroectodermal tumour, juvenile intestinal hamartomatous polyps and Wilms tumour (Foulkes et al, 2011; Slade et al, 2011; Choong et al, 2012).
Table 1. Classification of non-epithelial and miscellaneous gonadal tumours

\section{Sex cord-stromal tumours}

Granulosa-stromal cell tumours

Granulosa cell tumour

Adult type

Juvenile type

Thecoma-Fibroma group

Thecoma

Fibroma-fibrosarcoma

Sclerosing stromal tumour

Sertoli-stromal cell tumours

Sertoli cell tumour

Stromal-Leydig cell tumour

Sertoli-Leydig cell tumour (androblastoma)

Sex cord-stromal tumours of mixed or unclassified type

Sex cord-tumour with annular tubules

Gynandroblastoma

Sex cord-stromal tumour, unclassified

Steroid cell tumours

Leydig cell tumours

Hilus cell tumour

Leydig cell tumour, non-hilar type

Germ cell tumours

Primitive germ cell tumours

Dysgerminoma

Yolk sac tumour

Embryonal carcinoma

Polyembryoma

Choriocarcinoma

Teratoma

Mature

Immature

Monodermal and highly specialised types

Mixed germ cell tumours

Germ cell sex cord-stromal tumours

Gonadoblastoma

Mixed germ cell-sex cord-stromal tumour

Miscellaneous ovarian tumours

Small cell carcinoma, hypercalcaemic type

Wilms tumour

Soft tissue tumours not specific to the ovary

Embryonal rhabdomyosarcoma

Adapted from Scully, 1987

Somatic mutations in DICER1 exist in the tumours of many of the patients who harbour germline mutations in this gene: such mutations were found in 30 of 102 (29\%) of non-epithelial ovarian tumours. These somatic mutations affected the metal-binding sites of the RNase IIIb domain, and have been named 'hotspots' (Heravi-Moussavi et al, 2012). Furthermore, four of the patients with hotspot mutations from whom constitutional DNA was tested harboured an additional deleterious germline mutation.

Given that in the previous paper, discovery-based whole-exome sequencing of 14 non-epithelial ovarian tumours revealed deleterious somatic mutations only in the RNase III domains of DICER1 (Heravi-Moussavi et al, 2012), and that a previous study, in which the entire DICER1 gene was sequenced in 191 sporadic Wilms tumours, reported that three of the five identified missense 
mutations were in the RNase IIIb domain (Wu et al, 2013), we accordingly focussed on the RNase III domains only. We sequenced the RNase IIIa and IIIb domains of DICER1 in 154 non-epithelial ovarian and testicular tumours and in 43 extragonadal GCTs. In doing so, we provide a comprehensive follow-up of the initial study (Heravi-Moussavi et al, 2012). In sequencing a wide variety of tumour types, we refine the previous results, extend the phenotypes associated with somatic DICER1 mutations in nonepithelial gonadal tumours and provide new data on the prevalence of DICER 1 mutations in these and other related tumours, such as extra-gonadal GCTs, ERMS and small-cell carcinoma of the ovary, hypercalcaemic type.

\section{MATERIALS AND METHODS}

Samples. The study was approved by the relevant institutional review boards: KEMH Ethics Board, WA on 18/06/2012, reference 1986/EW in Perth, the Multicenter Research Ethics Committee (ref: 02/4/071) and Local Research Ethics Committee (ref: 01/128) in Cambridge, the ethics board of the HeinrichHeine-University in Düsseldorf, and the Institutional Review Board of the Faculty of Medicine of McGill University no. A00M117-11A in Montreal. Participants provided written informed consent where applicable. Samples were acquired and tested in accordance with approvals obtained at the aforementioned sites. Eighty-six DNA samples from formalin-fixed paraffin-embedded (FFPE) gonadal tumours and 69 DNA samples from fresh-frozen gonadal tumours, as well as 32 constitutional DNA samples from these patients were collected and analysed (Supplementary Table S1). Of the total 154 gonadal tumours, 135 occurred in patients that were phenotypically female (Table $2 \mathrm{a}$ ) and 19 arose in those that were phenotypically male (Table $2 \mathrm{~b}$ ). In addition, as few genetic studies have been performed on extra-gonadal GCTs, 43 extra-gonadal GCTs were analysed from 17 male and 26 female patients (Supplementary Figure S2). Furthermore, eight miscellaneous ovarian tumours were studied: seven cases of small-cell carcinoma of the ovary, hypercalcemic type and one ERMS. All tumours were reviewed by pathologists at the institution from which the samples were acquired or by central reference pathologists (Supplementary Table S1 and Supplementary Materials). The gonadal tumour types analysed are summarised in Tables $2 \mathrm{a}$ and $\mathrm{b}$.

DNA extraction and Sanger sequencing. DNA was extracted from FFPE tumour samples using 3-5 slides of $10 \mu$ m thick tumour tissue with the QIAamp DNA FFPE Tissue Kit (QIAGEN, Toronto, ON, Canada) according to protocol. DNA from freshfrozen tumour tissues was extracted using the DNeasy Blood and Tissue Kit (QIAGEN, Hilden, Germany). Sanger sequencing was used to screen the RNase IIIa and IIIb domains of DICER1 in the tumour samples. Primer pairs for PCR amplification and sequencing were designed using Primer3 (http://frodo.wi.mit.edu/) to flank exons (Supplementary Materials). The sequences were then filtered using OligoCalc software (Kibbe, 2007) to avoid hairpin formation and UCSC in silico PCR software to ensure yield of a single product. DNA from any FFPE sample in which a mutation was found was extracted twice independently and the PCR was repeated at least twice from each independent extraction using QIAGEN HotStarTaq, $10 \mathrm{mM}$ dNTP and $10 \times$ PCR buffer reagents with $1.4 \mu \mathrm{l}$ of $20 \mu \mathrm{M}$ primers in a $50-\mu \mathrm{l}$ reaction. Thermocycler parameters can be found in the Supplementary Materials. PCR products were purified and sequenced by conventional Sanger methods by the McGill University and Genome Quebec Innovation Centre. Sequences were analysed visually using Lasergene Version 10 (DNASTAR, Madison, WI, USA).
Table 2a. Ovarian tumours: histologial subtypes and frequency of DICER1 mutations

\begin{tabular}{|l|c|}
\hline Tumours studied & $\begin{array}{c}\text { Samples with mutation/total } \\
\text { cases studied (\%) }\end{array}$ \\
\hline Sex cord-stromal tumours ${ }^{\text {a }}$ & $9 / 28(32)$ \\
\hline Sertoli-Leydig cell tumour & $8 / 15(53)$ \\
Juvenile granulosa cell tumour & $0 / 4$ \\
Unclassified sex cord-stromal tumour & $1 / 7(14)$ \\
Leydig cell tumour & $0 / 1$ \\
Sex cord-stromal tumour with & $0 / 1$ \\
annular tubules & \\
\hline Germ cell tumours & \\
\hline Teratoma-mature & $3 / 99(3)$ \\
Teratoma-immature & $0 / 5$ \\
Yolk sac tumour & $0 / 15$ \\
Embryonal carcinoma & $0 / 20$ \\
Mixed malignant germ cell tumour & $0 / 1$ \\
Dyserminoma/gonadoblastoma & $2 / 14(17)$ \\
Dysgerminoma & $1 / 5(20)$ \\
\hline Miscellaneous & $0 / 39$ \\
\hline Embryonal rhabdomyosarcoma & $0 / 8$ \\
Small-cell carcinoma of the ovary, & $0 / 1$ \\
hypercalcaemic type & $0 / 7$ \\
\hline Total & \\
\hline a Ages 7 months to 66 years (median age 16 years). \\
bAges birth to 39 years (median age 17 years). \\
cAges 15 to 46 years (median 18 years). \\
\hline
\end{tabular}

Table 2b. Testicular tumours: histologial subtypes and frequency of DICER1 mutations

\begin{tabular}{|l|c|}
\hline Tumours studied & $\begin{array}{c}\text { Samples with mutation/total } \\
\text { cases studied (\%) }\end{array}$ \\
\hline Germ cell tumours $^{\text {a }}$ & $2 / 19(10)$ \\
\hline Teratoma-mature & $0 / 2$ \\
Teratoma-immature & $0 / 1$ \\
Yolk sac tumour & $1 / 7(14)$ \\
Embryonal carcinoma & $0 / 1$ \\
Mixed malignant germ cell tumour & $1 / 5(20)$ \\
Seminoma & $0 / 3$ \\
\hline Total & $2 / 19(10)$ \\
\hline aAges 10 months to 25 years (median age 17 years). \\
\hline
\end{tabular}

\section{RESULTS}

Using Sanger sequencing, we analysed the RNase III domains of DICER1 in 154 gonadal tumour samples of various types (Tables 2a and b) and in 43 extra-gonadal tumours (Supplementary Figure S2). We found 14 heterozygous mutations in DICER1 affecting five different residues of RNase IIIb: E1705, D1709, E1788, D1810 and E1813 (Figure 1, Table 3). Although most of the codon changes were predicted to cause a non-synonymous amino-acid change, one variant (c.5438A $>\mathrm{G}$ ) was recently shown to cause skipping of the entire exon 25 , leading to a frameshift (p.E1788fsX41) (Wu et al, 2013). Matched constitutional DNA was not available for most tumours with mutations but in all five patients whose constitutional DNA was tested, the mutations were somatic. 

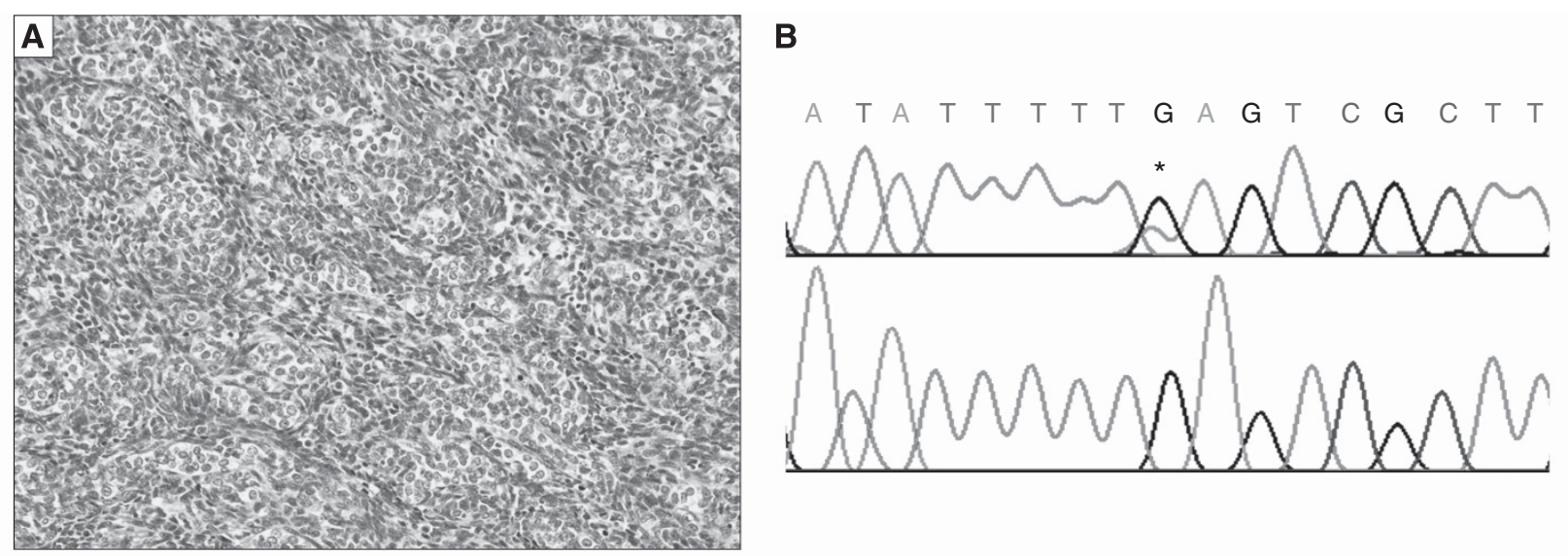

C

DICER

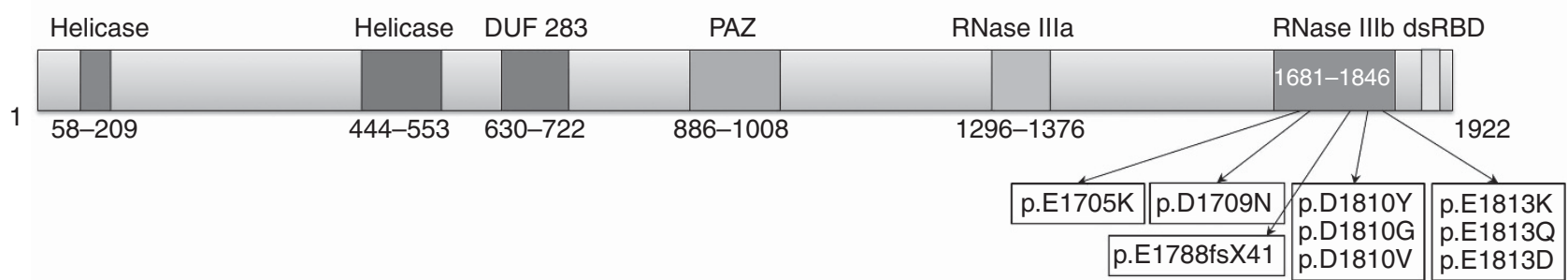

Figure 1. Diagram of DICER protein and representative SLCT with mutation. (A) Example of poorly differentiated SLCT harbouring a hotspot mutation in DICER1, $20 \times$. (B) Top: hotspot mutation c.5437G > A found in (A), * denotes mutation. Bottom: wild-type. (C) Schematic of DICER protein (NP_001258211.1), listing all predicted amino-acid changes found in analysed samples. Numbers indicate amino-acid position.

\begin{tabular}{|c|c|c|c|c|}
\hline $\begin{array}{l}\text { Codon } \\
\text { change }\end{array}$ & Tumour types & $\begin{array}{l}\text { Age of } \\
\text { patient in } \\
\text { years (gender) }\end{array}$ & $\begin{array}{l}\text { Protein } \\
\text { change }\end{array}$ & Previously reported (tumour types) \\
\hline c.5113G $\rightarrow$ A & Unclassified SCST & $54(\mathrm{~F})$ & p.E1705K & $\begin{array}{c}\text { Yes (ERMS, SLCT) } \\
\text { (Heravi-Moussavi et al, 2012) }\end{array}$ \\
\hline$c .5125 \mathrm{G} \rightarrow \mathrm{A}$ & SLCT & $21(\mathrm{~F})$ & p.D1709N & $\begin{array}{c}\text { Yes (SLCT,TGCT,YST) } \\
\text { (Heravi-Moussavi et al, 2012) }\end{array}$ \\
\hline $\mathrm{c.} 5428 \mathrm{G} \rightarrow \mathrm{T}$ & Mixed GCT (YST/IT) & $27(\mathrm{~F})$ & p.D1810Y & $\begin{array}{c}\text { Yes (SLCT, ERMS, MT) } \\
\text { (Heravi-Moussavi et al, 2012, Wu et al, 2013) }\end{array}$ \\
\hline $\mathrm{c} .5429 \mathrm{~A} \rightarrow \mathrm{G}^{\mathrm{a}}$ & Mixed gonadoblastoma/dysgerminoma & $15(F)$ & p.E1788fs $* 41$ & No \\
\hline c. $5429 \mathrm{~A} \rightarrow \mathrm{T}$ & SLCT with components of JGCT & $16(F)$ & p.D1810V & No \\
\hline c. $5437 \mathrm{G} \rightarrow \mathrm{A}$ & SLCT & $32(\mathrm{~F})$ & p.E1813K & $\begin{array}{c}\text { Yes (SLCT) } \\
\text { (Heravi-Moussavi et al, 2012) }\end{array}$ \\
\hline$c .5437 \mathrm{G} \rightarrow \mathrm{C}$ & $\begin{array}{l}\text { SLCT } \\
\text { SLCT }\end{array}$ & $\begin{array}{l}13(F) \\
20(F)\end{array}$ & p.E18130 & $\begin{array}{c}\text { Yes (SLCT) } \\
\text { (Heravi-Moussavi et al, 2012) }\end{array}$ \\
\hline $\mathrm{c} .5438 \mathrm{~A} \rightarrow \mathrm{G}^{\mathrm{b}}$ & $\begin{array}{l}\text { Mixed GCT (dysgerminoma/YST) } \\
\text { Mixed GCT (embryonal carcinoma/IT/choriocarcinoma) } \\
\text { YST } \\
\text { SLCT }\end{array}$ & $\begin{array}{l}9(\mathrm{~F}) \\
12(\mathrm{M}) \\
1(\mathrm{M}) \\
24(\mathrm{~F})\end{array}$ & p.E1788fs*41 & $\begin{array}{l}\text { Yes (SLCT, WT) } \\
\text { (Heravi-Moussavi et al, 2012; Wu et al, 2013) }\end{array}$ \\
\hline c.5439G $\rightarrow$ C & $\begin{array}{l}\text { SLCT } \\
\text { SLCT }\end{array}$ & $\begin{array}{l}16(F) \\
30(F)\end{array}$ & p.E1813D & No \\
\hline \multicolumn{5}{|c|}{ 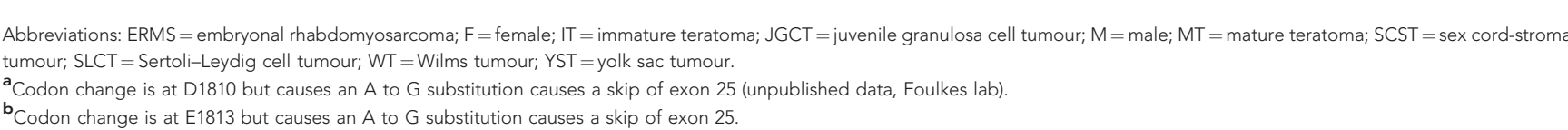 } \\
\hline
\end{tabular}

The majority of mutations (8/14) were detected in ovarian SLCTs. One other mutation was observed in an unclassified SCST. Five mutations were found in gonadal GCTs (three females and two males). One of these mutations was in a yolk sac tumour (male), one in a mixed dysgerminoma/gonadoblastoma (mostly dysgerminoma, female) and three in mixed malignant GCTs, two 
of which had a yolk sac tumour component (both females). Three of the five mutated GCTs harboured the same variation (c.5438A $>\mathrm{G}$ ). No mutations were detected in any of the 43 extra-gonadal GCTs, in seven cases of small-cell carcinoma of the ovary, hypercalcaemic type or in the single case of ovarian ERMS. There was no significant difference between the ages of the patients with DICER 1 mutations (median age 18, range 20 months-54 years) and those without (median age 17 years, range birth-66 years), $(P=0.72$, Student's two-tailed $t$-test). The results are summarised in Tables $2 \mathrm{a}$ and $\mathrm{b}$ and Supplementary Table S1.

\section{DISCUSSION}

DICER1 mutations in non-epithelial gonadal tumours. We found mutations in the RNase IIIb region of DICER1 in 8 of 15 (53\%) of ovarian SLCTs and in 14 of 154 (9\%) of all gonadal tumours studied. Our results in SLCTs are consistent with the previous study (Heravi-Moussavi et al, 2012), in which DICER1 hotspot mutations were identified in $26 / 43$ SLCTs (60\%). We also analysed seven unclassified SCSTs, and found one mutation. This demonstrates that in tumours where histological classification is difficult, such as in some undifferentiated SCSTs, mutation analysis may aid tumour classification. In addition, we tested seven cases of small-cell carcinoma of the ovary, hypercalcaemic type and one case of ovarian ERMS, but did not find any DICER1 hotspot mutations. Our study also included extra-gonadal GCTs and a large series of ovarian GCTs of different histological types, and therefore we were able to expand upon earlier findings in these tumours.

Heravi-Moussavi et al (2012) identified mutations in $2 / 15$ ovarian yolk sac tumours, whereas we did not find mutations in any of the 20 cases that we studied. However, our two DICER1mutated mixed malignant ovarian GCTs did contain yolk sac components. Consistent with the findings of Heravi-Moussavi et al (2012), we analysed 44 dysgerminomas (five of which were associated with gonadoblastoma) and found only a single mutation, allowing us to conclude that mutations in DICER1 hotspot mutations are rare in dysgerminomas but do occasionally occur.

Another recent study reported that somatic DICER1 mutations in testicular GCTs are rare (De Boer et al, 2012). Although HeraviMoussavi et al (2012) found a hotspot mutation in 1/14 testicular GCTs analysed, De Boer et al (2012) identified a mutation in just $1 / 96$ tumours. In comparison, mutations were present in $2 / 19$ testicular GCTs (one YST, one mixed malignant GCT) in the present series. Therefore, overall, somatic hotspot mutations in DICER1 have been identified in 4/129 (3\%) testicular GCTs investigated to date.

Sex cord-stromal tumours, GCTs and the DICER1 syndrome. As the discovery of the DICER1 syndrome in patients with PPB, several studies have demonstrated the association between germline DICER1 mutations and various types of ovarian SCSTs and GCTs (Rio Frio et al, 2011; Schultz et al, 2011; Slade et al, 2011). SLCTs are by far the most common non-epithelial ovarian tumour associated with the DICER1 syndrome, and it is not clear whether germline DICER1 mutations predispose to GCTs. Before identification of the responsible gene, a study described two families in which relatives of patients with PPB were diagnosed with testicular GCTs (Priest et al, 1996). Furthermore, 1 dysgerminoma and 3 seminomas have been reported in relatives of patients with DICER1 germline mutations (Schultz et al, 2011), but no DICER1 germline mutation was found in the only seminoma patient for which genetic information was available. Moreover, full sequencing of DICER1 has revealed only a single SNV resulting in p.Q1580H in 228 probands with a GCT, at least 171 of whom had a positive family history of GCT (Slade et al, 2011; Sabbaghian et al, 2013).
All but one of the mutations we found were in either a tumour definitely associated with the DICER1 syndrome (SCSTs), or in a GCT with a dysgerminoma or yolk sac component. It remains unclear whether somatic DICER 1 mutations can be causally related to dysgerminomas or pure yolk sac tumours, but if they are, the mutations occur substantially less frequently than in SCSTs, and germline mutations in DICER1 are rarely associated with susceptibility to GCTs.

Mechanism of tumorigenesis. As previously reported, the mutations we found were clustered around the $\mathrm{Mg}^{2}+$ metal-binding sites of the RNase IIIb domain (Heravi-Moussavi et al, 2012). However, although these authors detected more mutations at D1709, we found that the majority occurred at D1810 and E1813. It was originally believed that DICER1 mutations induced neoplasia via a haploinsufficient mechanism (Kumar et al, 2009), but more recent studies have shown that some patients with deleterious mutations on one allele of the gene also have a somatic, non-truncating, mutation on the other allele (Heravi-Moussavi et al, 2012; Wu et al, 2013). The specific locations of the mutations are more reminiscent of dominantly-acting oncogenes and it is likely that the hotspot-mutated alleles produce a viable, albeit dysfunctional, protein (Heravi-Moussavi et al, 2012). As the RNase IIIb domain requires the binding of two $\mathrm{Mg}^{2+}$ ions to catalyse the cleavage of the miRNA, improper binding due to an amino-acid change at any of these sites would presumably prevent DICER from processing its target miRNA. Recently, a model has been proposed whereby $5 p$ strand miRNAs are not produced if the DICER protein is mutated at the RNase IIIb domain (Anglesio et al, 2013). As $5 \mathrm{p}$ strand miRNAs are more abundant than $3 p$ strand miRNAs in targeting human mRNAs, loss of the former is likely to lead to increased levels of key proto-oncogenic mRNAs, potentiating tumour development (Anglesio et al, 2013).

This model may explain how such mutations result in tumorigenesis, but questions still remain as to (1) why germline DICER1 mutations predispose to highly specific types of very rare cancers and (2) how identical somatic mutations can cause various different types of benign and malignant tumours. It has been suggested that as many of the tumours related to the DICER1 syndrome possess an embryonal or primitive appearance, perhaps the effect of germline mutations is restricted to certain cell types during development (Heravi-Moussavi et al, 2012). The tumours associated with DICER1 syndrome often occur in younger children, suggesting a developmental relationship. However, the contribution of DICER1 mutations to the different tumours of the syndrome is variable. Although germline DICER1 mutations may contribute significantly to cystic nephroma and SLCTs (Bahubeshi et al, 2010; Slade et al, 2011), they do not have as great an impact on the occurrence of Wilms tumour (Bahubeshi et al, 2010; Slade et al, 2011; Wu et al, 2013). DICER-null embryonic stem cells usually do not survive, but several cell-type specific conditional DICER1 knockout models exist and experiments suggest that only a subset of differentiated cells are tolerant to a complete loss of DICER1 (Gonzalez and Behringer, 2009; Iida et al, 2011; Nagalakshmi et al, 2011). It is plausible that the tissues in which tumours develop more frequently rely more on the function of DICER and miRNAs during development. Indeed, DICER has been shown to be necessary for postnatal differentiation and development of Müllerian duct mesenchyme-derived tissues of the female reproductive tract (Gonzalez and Behringer, 2009), as well as for nephrogenic development (Nagalakshmi et al, 2011).

Genetic studies such as those described in the current paper are important in potentially modifying or furthering tumour classification, as some tumours with similar histological appearances may have distinct genetic alterations. In the present study, one mutation-positive tumour had been diagnosed as an unclassified SCST, but it is possible that this tumour was in fact a poorly 
differentiated SLCT. There is a constant evolution in the classification of neoplasia, and the identification of specific molecular abnormalities has the potential to enhance diagnostic accuracy and, ultimately, provide a rational approach to the development of novel treatment strategies (Bisogno et al, 2012). With advances in targeted therapies, it is likely that the identification of molecular alterations in gonadal SCSTs and GCTs will have increasing impact on diagnosis, treatment and outcome.

The two main limitations of our study were the small sample size for some of the histological subtypes, and the inability to test germline DNA in all of the patients with mutation-positive tumours to determine whether the identified mutations were germline or somatic events.

\section{CONCLUSION}

Through Sanger sequencing of 154 non-epithelial ovarian and testicular tumours, DICER1 mutations were detected in $8 / 15$ SLCTs, but only a small number of mutations in other types of tumours. Our data, when combined with the only previous publication on this subject (Heravi-Moussavi et al, 2012), demonstrate that $34 / 58$ SLCTs (59\%) possess RNase IIIb DICER1 mutations. Due to the heterogeneous nature of SCSTs, the genetic differences between the tumours may aid in classification and provide new therapeutic approaches. A mutation was identified in one unclassified SCST, demonstrating that genetic testing may aid in the diagnosis of histologically problematic or previously unclassifiable tumour types.

The exact function of the observed DICER 1 mutations in the formation and progression of neoplasms presenting in patients with the DICER1 syndrome remains unknown. If aberrant miRNAs have a more general causal role in these tumours, it is possible that the tumours without DICER1 mutations have alterations in other factors in the miRNA processing pathway. Further investigations are likely to shed light on the exact role of these DICER1 mutations in the formation of these rare tumours and other types of neoplasia, whether it be via miRNA maturation or through other DICER1-related functions.

\section{ACKNOWLEDGEMENTS}

We dedicate this paper to the late Dr Aleksander Talerman, who worked for many years studying ovarian GCTs and whose contribution helped make this work possible. We thank Ms Nancy Hamel for overseeing the wet lab experiments and Dr Marc Tischkowitz and Mr François Plourde for aiding in the collection of sporadic tumour samples. We would like to thank Dr Guy Van Vliet, and Dr R Sharma for supplying samples and Dr John R Priest for reading the manuscript. This research was made possible thanks to the support from the Lady Davis Institute/TD Bank Studentship Award and les Fonds de Recherche du Québec-Santé to LW; from the McGill Integrated Cancer Research Training Program to JM; from Marsha Rivkin Center for Ovarian Cancer Research and Susan G Komen for the Cure to WDF and the Canadian Institute of Health Research to DGH. We would like to acknowledge the support of the UK Children's Cancer and Leukaemia Group (CCLG) Tumour Bank and the Tumour Bank of the german MAKEI study, which is supported by the Barbara and Hubertus Trettner Foundation.

\section{CONFLICT OF INTEREST}

The authors declare no conflict of interest.

\section{REFERENCES}

Anglesio MS, Wang Y, Yang W, Senz J, Wan A, Heravi-Moussavi A, Salamanca C, Maines-Bandiera S, Huntsman DG, Morin GB (2013) Cancer-associated somatic DICER1 hotspot mutations cause defective miRNA processing and reverse-strand expression bias to predominantly mature $3 p$ strands through loss of $5 p$ strand cleavage. J Pathol 229: 400-409.

Arora RS, Alston RD, Eden TOB, Geraci M, Birch JM (2012) Comparative incidence patterns and trends of gonadal and extragonadal germ cell tumors in England, 1979 to 2003. Cancer 118: 4290-4297.

Bahubeshi A, Bal N, Rio Frio T, Hamel N, Pouchet C, Yilmaz A, Bouron-Dal Soglio D, Williams GM, Tischkowitz M, Priest JR, Foulkes WD (2010) Germline DICER1 mutations and familial cystic nephroma. J Med Genet 47: 863-866.

Bahubeshi A, Tischkowitz M, Foulkes WD (2011) miRNA processing and human cancer: DICER1 cuts the mustard. Sci Transl Med 3: $111 \mathrm{ps} 46$.

Bisogno G, Cecchetto G, Ferrari A (2012) Very rare tumours in paediatric age-from 'Tumori Rari in Età Pediatrica' to the European Cooperative Study Group for paediatric rare tumours. Eur Oncol Haematol 8: 130-134.

Choong CS, Priest JR, Foulkes WD (2012) Exploring the endocrine manifestations of DICER1 mutations. Trends Mol Med 18: 503-505.

De Boer C, Eini R, Gillis A, Stoop H, Looijenga L, White S (2012) DICER1 RNase IIIb domain mutations are infrequent in testicular germ cell tumours. BMC Res Notes 5: 569 .

Foulkes WD, Bahubeshi A, Hamel N, Pasini B, Asioli S, Baynam G, Choong CS, Charles A, Frieder RP, Dishop MK, Graf N, Ekim M, Bouron-Dal Soglio D, Arseneau J, Young RH, Sabbaghian N, Srivastava A, Tischkowitz MD, Priest JR (2011) Extending the phenotypes associated with DICER1 mutations. Hum Mutat 32: 1381-1384.

Giambartolomei C, Mueller CM, Greene MH, Korde LA (2009) A mini-review of familial ovarian germ cell tumors: An additional manifestation of the familial testicular germ cell tumor syndrome. Cancer Epidemiol 33: 31-36.

Gonzalez G, Behringer RR (2009) Dicer is required for female reproductive tract development and fertility in the mouse. Mol Reprod Dev 76: 678-688.

Heravi-Moussavi A, Anglesio M, Cheng S, Senz J, Yang W, Prentice L, Fejes A, Chow C, Tone A, Kalloger S, Hamel N, Roth A, Ha G, Wan A, Maines-Bandiera S, Salamanca C, Pasini B, Clarke B, Lee A, Lee C, Zhao C, Young R, Aparicio S, Sorensen P, Woo M, Boyd N, Jones S, Hirst M, Marra M, Gilks B, Shah SP, Foulkes WD, Morin GB, Huntsman DG (2012) Recurrent somatic DICER1 mutations in nonepithelial ovarian cancers. N Engl J Med 366: 234-242.

Hill DA, Ivanovich J, Priest JR, Gurnett CA, Dehner LP, Desruisseau D, Jarzembowski JA, Wikenheiser-Brokamp KA, Suarez BK, Whelan AJ, Williams G, Bracamontes D, Messinger Y, Goodfellow PJ (2009) DICER1 mutations in familial pleuropulmonary blastoma. Science 325: 965.

Iida A, Shinoe T, Baba Y, Mano H, Watanabe S (2011) Dicer plays essential roles for retinal development by regulation of survival and differentiation. Invest Ophthalmol Vis Sci 52: 3008-3017.

Kibbe WA (2007) OligoCalc: an online oligonucleotide properties calculator Nucleic Acids Res 35 (webserver issue); e-pub ahead of print 25 May 2007.

Kumar MS, Pester RE, Chen CY, Lane K, Chin C, Lu J, Kirsch DG, Golub TR, Jacks T (2009) Dicerl functions as a haploinsufficient tumor suppressor. Genes Dev 23: 2700-2704.

Low JJH, Ilancheran A, Ng JS (2012) Malignant ovarian germ-cell tumours. Best Pract Res Clin Obstet Gynaecol 26: 347-355.

Lu J, Getz G, Miska EA, Alvarez-Saavedra E, Lamb J, Peck D, Sweet-Cordero A, Ebert BL, Mak RH, Ferrando AA, Downing JR, Jacks T, Horvitz HR, Golub TR (2005) MicroRNA expression profiles classify human cancers. Nature 435: 834-838.

Luis IV, Coleman R (2011) Ovarian germ cell malignancy: a heterogeneous tumour requiring supra-regional management. Eur J Gynaecol Oncol 32: 387-392.

Murchison EP, Hannon GJ (2004) miRNAs on the move: miRNA biogenesis and the RNAi machinery. Curr Opin Cell Biol 16: 7.

Nagalakshmi VK, Ren Q, Pugh MM, Valerius MT, Mcmahon AP, Yu J (2011) Dicer regulates the development of nephrogenic and ureteric compartments in the mammalian kidney. Kidney Int 79: 317-330.

Priest JR, Watterson J, Strong L, Huff V, Woods WG, Byrd RL, Friend SH, Newsham I, Amylon MD, Pappo A, Mahoney DH, Langston C, Heyn R, Kohut G, Freyer DR, Bostrom B, Richardson MS, Barredo J, Dehner LP 
(1996) Pleuropulmonary blastoma: a marker for familial disease. J Pediatr 128: $220-224$.

Rio Frio T, Bahubeshi A, Kanellopoulou C, Hamel N, Niedziela M, Sabbaghian N, Pouchet C, Gilbert L, O'brien PK, Serfas K, Broderick P, Houlston RS, Lesueur F, Bonora E, Muljo S, Schimke RN, Bouron-Dal Soglio D, Arseneau J, Schultz KA, Priest JR, Nguyen V-H, Harach HR, Livingston DM, Foulkes WD, Tischkowitz M (2011) DICER1 mutations in familial multinodular goiter with and without ovarian Sertoli-Leydig cell tumors. JAMA 305: 68-77.

Sabbaghian N, Bahubeshi A, Shuen A, Kanetsky P, Tischkowitz M, Nathanson K, Foulkes W (2013) Germ-line DICER1 mutations do not make a major contribution to the etiology of familial testicular germ cell tumours. BMC Res Notes 6: 127.

Schneider DT, Calaminus G, Wessalowksi R, Pathmanathan R, Selle B, Sternschulte W, Harms D, Göbel U (2003) Ovarian sex cord-stromal tumors in children and adolescents. J Clin Oncol 21: 2357-2363.

Schultz KaP, Pacheco MC, Yang J, Williams GM, Messinger Y, Hill DA, Dehner LP, Priest JR (2011) Ovarian sex cord-stromal tumors, pleuropulmonary blastoma and DICER1 mutations: a report from the International Pleuropulmonary Blastoma Registry. Gynecol Oncol 122: 246-250.

Scully RE (1987) Classification of human ovarian tumors. Environ Health Perspect 73: 15-25.

Slade I, Bacchelli C, Davies H, Murray A, Abbaszadeh F, Hanks S, Barfoot R, Burke A, Chisholm J, Hewitt M, Jenkinson H, King D, Morland B, Pizer B,
Prescott K, Saggar A, Side L, Traunecker H, Vaidya S, Ward P, Futreal PA, Vujanic G, Nicholson AG, Sebire N, Turnbull C, Priest JR, Pritchard-Jones K, Houlston R, Stiller C, Stratton MR, Douglas J, Rahman N (2011) DICER1 syndrome: clarifying the diagnosis, clinical features and management implications of a pleiotropic tumour predisposition syndrome. J Med Genet 48: 273-278.

Talerman A, Vang R (2011) Germ Cell Tumors of the Ovary. In Blaustein's Pathology of the Female Genital Tract. 6th edn. Kurman R. J., Ellenson L. H., Ronnett B. M. (eds) Springer: New York, NY, USA, pp 847-907.

Wu MK, Sabbaghian N, Xu B, Addidou-Kalucki S, Bernard C, Zou D, Reeve AE, Eccles M, Cole C, Choong CS, Charles A, Tan TY, Iglesias DM, Goodyer PR, Foulkes WD (2013) Biallelic DICER1 mutations occur in Wilms tumours. J Pathol 230: 154-164.

Young RH (2011) Sex Cord-stromal, steroid cell, and other ovarian tumors with endocrine, paraendocrine, and paraneoplastic manifestations. In Blaustein's Pathology of the Female Genital Tract. 6th edn. Kurman R. J., Ellenson L. H., Ronnett B. M. (eds) Springer: New York, NY, USA, pp 785-846.

This work is published under the standard license to publish agreement. After 12 months the work will become freely available and the license terms will switch to a Creative Commons AttributionNonCommercial-Share Alike 3.0 Unported License.

Supplementary Information accompanies this paper on British Journal of Cancer website (http://www.nature.com/bjc) 